\title{
Knowledge, attitudes and beliefs of women in the reproductive age towards prenatal screening for congenital malformations, Alexandria-Egypt
}

\author{
Rehab Elsaid Nour Eldin Youssef ${ }^{1 *}$, Heba Taha El-Weshahi ${ }^{2}$, Mona Hamdy Ashry ${ }^{2}$
}

\begin{abstract}
${ }^{1}$ Department of Obstetrics and Gynecology, ${ }^{2}$ Department of Public Health, Faculty of Medicine, Alexandria University, Alexandria, Egypt
\end{abstract}

Received: 07 February 2017

Revised: 13 February 2017

Accepted: 23 March 2017

\section{*Correspondence:}

Dr. Rehab Elsaid Nour Eldin Youssef,

E-mail: rehabnoureidin@gmail.com

Copyright: $\odot$ the author(s), publisher and licensee Medip Academy. This is an open-access article distributed under the terms of the Creative Commons Attribution Non-Commercial License, which permits unrestricted non-commercial use, distribution, and reproduction in any medium, provided the original work is properly cited.

\section{ABSTRACT}

Background: The study was conducted to explore the Egyptian women's attitudes toward the prenatal screening (PNS) for congenital malformations and termination of pregnancy if medically indicated and assessing their knowledge and beliefs regarding prenatal screening.

Methods: A total of 351 Egyptian women in the reproductive age giving birth to at least one child completed a structured questionnaire to assess their knowledge of prenatal diagnosis and their willingness to undergo prenatal screening as well as their opinions on termination of pregnancy if medically indicated. Women's beliefs were also assessed.

Results: More than half of studied women (52.71\%) are lacking knowledge about the availability of the accurate tests for prenatal screening of congenital malformations. After giving information about PNS, more than three quarters (77.5\%) of the studied women held positive attitudes toward the prenatal screening for congenital malformations. The other one quarter was either refusing or not sure about their opinion (4.6\% and $17.9 \%$ respectively). Only $58.7 \%$ accepting termination of pregnancy if medically indicated. Positive attitude towards PNS was significantly higher among females with older age $(\mathrm{P}=0.019)$ as well as those of higher social class as indicated by higher level of education $(\mathrm{p}=0.026)$, urban residency $(\mathrm{p}=0.046)$ and working women $(\mathrm{p}=0.005)$. Perceived seriousness of congenital malformations and believing in the importance of early detection of such condition were the significant motives to undergo PNS.

Conclusions: There is marked lack of knowledge about the prenatal screening tests among the studied women. After giving information about PNS, most of them shows a positive attitude towards carrying out these tests and about half of them reported their acceptance for termination of pregnancy if medically indicated based on prenatal diagnosis of sever congenital malformations. Emphasis national needs for health education programs about PNS importance and development of well-structured national program for PNS.

Keywords: Attitudes, Beliefs, Congenital malformations/anomalies, Knowledge, Prenatal screening, Termination of pregnancy

\section{INTRODUCTION}

Major congenital malformations affect an average of 2 to $3 \%$ of all live births which constitute about 3 million fetuses and infants born yearly. They result in about half million yearly deaths worldwide. On the other hand, survivors with congenital malformations require frequent hospitalizations as a result of their anomalies or associated complications. These hospitalizations account for $15 \%$ to $30 \%$ of all pediatric hospitalizations with estimated higher 
cost compared to other causes of hospitalization. ${ }^{1}$ In addition to both mortality and morbidity burden of congenital malformations, they have a major impact on the affected families as well as the community as a whole. ${ }^{2,3}$ With more focus on the affected communities, it was revealed that the majority of these malformations (up to 94\%) occur in middle and low income countries which reflect more closely the seriousness and the major impact of this problem on the affected families and countries. ${ }^{1,4}$

The causation of congenital malformation was categorized into four broad categories namely genetic causes, multifactorial, environmental factors and finally the unknown group which constitutes up to 40 to $60 \%$ of all malformations. This unknown group added the possibility of other risk factors as exposure to infectious agents, chemicals, medications, stress, low socioeconomic status...etc. ${ }^{1,5}$

Consanguinity plays an important role in both genetic and multifactorial causation of malformations. It increases the prevalence of rare genetic disorders and almost double the risk for congenital malformations and neonatal deaths in the first cousin marriages. ${ }^{6}$ In Arabic countries including Egypt, consanguineous marriages are very common culturally and this explains the problem of congenital malformations which becoming a major public health concern in these countries. In 2008, it was reported that the prevalence of congenital and genetic disorders among infants and young children in Egypt ranged from 2.8\% in urban areas to $8.4 \%$ in rural areas while the associated mortality reached $2.41 \%$ from total deaths. ${ }^{7,8}$

With the introduction of ultrasound in the 1970s and the routine use of it in the antenatal care visits for visualizing the fetus, advances in this technology and other medical technologies as genetic analysis and biochemical testing light the way up for prenatal screening and diagnosis for early detection of congenital malformations and genetic disorders even rare ones. ${ }^{9}$ Either biochemical screening or ultrasound screening, both will provide the women the opportunity to make reproductive choices and take decisions even potentially difficult ones as termination of pregnancy with respect to subjective variability, cultural, ethical and religious matters. It also offers women and their partners' information that may help them better prepare for the birth of their child, the option of delivery in a setting that will permit rapid access to specialist surgical or medical care. Moreover, studies showed that prenatal diagnosis provides pregnant women with information that may be associated with better psychological management. ${ }^{9-11}$

The present study was conducted to assess level of awareness of Egyptian women in the reproductive age about prenatal screening for congenital malformations and to explore their attitude towards prenatal testing and termination of pregnancy if medically indicated. Moreover, factors that might be associated with acceptance including women's perceptions and beliefs were identified.

\section{METHODS}

A cross-sectional survey was conducted. A systematic random sample of 400 married females in the reproductive age (15-49 years) who had at least one child was included. Those who completed the used data collection tool were 351 females. Females were approached at several obstetrics and gynecology healthcare centers in Alexandria including governmental, private and educational ones. Data collection started from April till end of July 2015.

A self-administered structured questionnaire was used to collect data from studied women. The first part included data regarding the personal characteristics namely age, level of education, residence, employment status, average monthly income, number of family members and number of rooms at home. Moreover, inquiries about consanguinity with husband as well as family and personal history of congenitally malformed child in their offspring were included. This followed by questions to assess their awareness regarding prenatal fetal screening for congenital malformations and the main sources of these information, as well as types of screening tests and their safety.

After completing this part, females were given information about prenatal testing for congenital anomalies, types of tests, their importance and their possible side effects. Then they were asked to fill the second part of the questionnaire which included questions to assess their attitude towards prenatal testing as well as termination of pregnancy if medically indicated.

Moreover, women's perceptions regarding seriousness of congenital malformations, importance of the early detection, susceptibility to have a malformed fetus and their ability to care for were assessed.

An approval was obtained from local Ethical committee. Each female were given a full explanation of the study methodology and aim before enrollment. Privacy and confidentiality of data were ensured all through conduction of research.

Data entry and analysis were done using PASW Statistics for Windows, Version 18.0. Chicago.

Description of the socio-demographic characteristics of the studied women, their level of awareness and attitudes were expressed using numbers and percentages from total.

Analytic statistics to verify the association between women's attitudes and their characteristics, history and perceptions were conducted using chi-square test for qualitative variables and student $\mathrm{t}$ test for quantitative ones. 5\% level of significance was used for interpretation of all results. 


\section{RESULTS}

The study included a total number of 351 women in the reproductive age (15-49 years).

\section{Knowledge of studied women about prenatal screening for congenital malformations}

Slightly more than half of studied women $(52.7 \%)$ were lacking knowledge about availability of accurate screening tests for congenital malformations prenatally.

Among those who were aware of availability of the tests, only $81.33 \%$ state correctly one or more of their types and $69.28 \%$ of them knew that the majority of tests are free from any side effects.

Regards the main source of knowledge about this area among the studied sample, medical personnel and mass media were the most commonly reported ones $(56.63 \%$, and $38.55 \%$ respectively).

However, all studied females are multigravida, only $29.5 \%$ of those who had a previous knowledge about PNS were asked by their physician to do one of these tests before (Table1).

Table 1: Knowledge of enrolled women about prenatal screening for congenital malformations.

\begin{tabular}{|c|c|c|}
\hline & $\mathbf{N}$ & $\%$ \\
\hline $\begin{array}{l}\text { Awareness of the availability of } \\
\text { accurate tests }\end{array}$ & 166 & 47.29 \\
\hline women who stated at least one test* & 135 & 81.33 \\
\hline $\begin{array}{l}\text { women carried out prenatal } \\
\text { screening before }\end{array}$ & 49 & 29.50 \\
\hline Reported safety of the tests* & 115 & 69.28 \\
\hline \multicolumn{3}{|l|}{ Sources of knowledge about PNS** } \\
\hline Physicians and medical personnel & 94 & 56.63 \\
\hline Mass Media & 64 & 38.55 \\
\hline Relatives & 37 & 22.29 \\
\hline Personal Readings/education & 19 & 11.45 \\
\hline No answer & 19 & 11.45 \\
\hline
\end{tabular}

$*(n=166)$ those who are aware of the availability of tests,

$* *$ Categories are not mutually exclusive.

\section{Attitude of women towards PNS and termination of pregnancy}

More than three quarters of women (77.5\%) showed positive attitude towards PNS if recommended by the physician however others are willing to undergo prenatal screening (PNS) if the physician recommends that. Others were either refusing or not sure about their opinion $(4.6 \%$ and $17.9 \%$ respectively). Regarding opinion of studied women about termination of pregnancy if medically indicated; only $58.7 \%$ of them were sure that they will accept. However, $14.8 \%$ refused and $26.5 \%$ were not sure (Table 2).
Table 2: Distribution of studied women according to their attitude towards prenatal screening and termination of pregnancy.

\begin{tabular}{|c|c|c|c|c|c|c|}
\hline \multirow{2}{*}{$\begin{array}{l}\text { Attitudes of } \\
\text { females }\end{array}$} & \multicolumn{2}{|c|}{ Accepting } & \multicolumn{2}{|c|}{ Not sure } & \multicolumn{2}{|c|}{$\begin{array}{l}\text { Not } \\
\text { accepting }\end{array}$} \\
\hline & No & $\%$ & No & $\%$ & No & $\%$ \\
\hline $\begin{array}{l}\text { Prenatal } \\
\text { screening for } \\
\text { congenital } \\
\text { malformations }\end{array}$ & 272 & 77.5 & 63 & 17.9 & 16 & 4.6 \\
\hline $\begin{array}{l}\text { Termination } \\
\text { of pregnancy } \\
\text { if medically } \\
\text { indicated }\end{array}$ & 206 & 58.7 & 93 & 26.5 & 52 & 14.8 \\
\hline
\end{tabular}

\section{Factors determine attitude of studied women towards PNS}

\section{Baseline characteristics}

The mean age among women who had a positive attitude towards screening willing to undergo screening was significantly higher than the mean age among the other group $(p=0.019)$. Moreover, The mean age at the time of the last pregnancy was significantly higher among those accepting screening as compared to those refusing it $(28.21 \pm 5.23$ versus $26.46 \pm 5.16)(\mathrm{p}=0.027)$.

Some socioeconomic determinants were significantly associated with the negative attitude among studied women namely lower level of education, rural residency and being a house wife $(\mathrm{P}=0.026,0.046,0.005$ respectively).

On the other hand, no significant difference was noted between women who accepting screening and those refusing regarding the crowding index and their reported average monthly income $(\mathrm{p}=0.388$ and 0.176 respectively).

Consanguinity with husbands was insignificantly associated with women's attitude towards prenatal screening $(\mathrm{p}=0.473)($ Table 3$)$.

\section{Family and personal history}

Having a positive personal or family history of getting a congenitally malformed child were insignificantly associated with having a positive attitude towards prenatal screening ( $\mathrm{p}=0.436$ and 0.460 respectively) (Table 4$)$.

\section{Beliefs and perceptions}

Perceived susceptibility to get a congenitally malformed child was insignificantly associated with their attitude towards prenatal screening $(\mathrm{p}=0.759)$. On the other hand, positive attitude was significantly higher among women perceiving seriousness of such condition $(\mathrm{p}=0.001)$. 
Table 3: Attitude of women towards PNS and their sociodemographic characteristics.

\begin{tabular}{|c|c|c|c|c|c|}
\hline \multirow{2}{*}{ Socio-demographic characteristics } & \multicolumn{2}{|c|}{ Accepting (272) } & \multicolumn{2}{|c|}{ Refusing or not sure (n=79) } & \multirow{2}{*}{ Test of significance } \\
\hline & no & $\%$ & no & $\%$ & \\
\hline \multicolumn{5}{|l|}{ Age in years } & \multirow{3}{*}{$\begin{array}{l}\mathrm{t}=2.355 \\
\mathrm{P}=0.019 *\end{array}$} \\
\hline Mean \pm SD & \multicolumn{2}{|c|}{$29.71 \pm 5.72$} & \multicolumn{2}{|c|}{$27.99 \pm 5.72$} & \\
\hline Min - Max & \multicolumn{2}{|c|}{$18-52$} & \multicolumn{2}{|c|}{$19-62$} & \\
\hline \multicolumn{6}{|l|}{ Age at last pregnancy } \\
\hline Mean \pm SD & \multicolumn{2}{|c|}{$28.21 \pm 5.23$} & \multicolumn{2}{|c|}{$26.46 \pm 5.16$} & \multirow{2}{*}{$\begin{array}{l}\mathrm{t}=2.230 \\
\mathrm{p}=0.027^{*}\end{array}$} \\
\hline Min-Max & \multicolumn{2}{|c|}{$16-42$} & \multicolumn{2}{|c|}{$17-38$} & \\
\hline \multicolumn{5}{|l|}{ Level of education } & \multirow{5}{*}{$\begin{array}{l}X^{2}=9.23 \\
P=0.026^{*}\end{array}$} \\
\hline Read and write & 14 & 58.3 & 10 & 41.7 & \\
\hline Basic education & 46 & 70.8 & 19 & 29.2 & \\
\hline Secondary education & 85 & 83.3 & 27 & 16.7 & \\
\hline University or higher & 127 & 84.7 & 23 & 15.3 & \\
\hline \multicolumn{5}{|l|}{ Residency } & \multirow{3}{*}{$\begin{array}{l}X^{2}=3.99 \\
P=0.046^{*}\end{array}$} \\
\hline Rural & 48 & 68.6 & 22 & 31.4 & \\
\hline Urban & 224 & 79.7 & 57 & 20.3 & \\
\hline \multicolumn{6}{|l|}{ Working status } \\
\hline Currently working & 89 & 87.3 & 13 & 12.7 & \multirow{2}{*}{$\begin{array}{l}X^{2}=7.856 \\
P=0.005^{*}\end{array}$} \\
\hline Housewife & 183 & 73.5 & 66 & 26.5 & \\
\hline \multicolumn{5}{|l|}{ Crowding index } & \multirow{3}{*}{$\begin{array}{l}\mathrm{t}=0.865 \\
\mathrm{P}=0.388^{\mathrm{ns}}\end{array}$} \\
\hline Mean $\pm \mathrm{SD}$ & 1.02 & 0.46 & 0.96 & & \\
\hline Min - Max & $0.5-$ & 67 & 0.4 & & \\
\hline \multicolumn{5}{|l|}{ Average monthly income } & \multirow{3}{*}{$\begin{array}{l}\mathrm{t}=1.356 \\
\mathrm{P}=0.176^{\mathrm{ns}}\end{array}$} \\
\hline Mean \pm SD & 2036 & -338.86 & 143 & & \\
\hline Min-Max & 500 & 5000 & 200 & & \\
\hline \multicolumn{5}{|l|}{ Consanguinity } & \multirow{3}{*}{$\begin{array}{l}X^{2}=0.516 \\
P=0.473\end{array}$} \\
\hline Yes & 52 & 74.3 & 18 & 25.7 & \\
\hline No & 220 & 78.3 & 61 & 21.7 & \\
\hline
\end{tabular}

Table 4: Attitude of women towards PNS and their past history of congenital anomalies.

\begin{tabular}{|c|c|c|c|c|c|}
\hline \multirow{2}{*}{ Obstetric history } & \multicolumn{2}{|c|}{ Accepting ( $n=272)$} & \multicolumn{2}{|c|}{ Refusing or not sure (n=79) } & \multirow{2}{*}{$\begin{array}{l}\text { Test of } \\
\text { significance }\end{array}$} \\
\hline & no & $\%$ & no & $\%$ & \\
\hline \multicolumn{5}{|c|}{ Family history of congenital anomalies } & \multirow{3}{*}{$\begin{array}{l}X^{2}=0.606 \\
P=0.436\end{array}$} \\
\hline Yes & 31 & 79.5 & 9 & 20.5 & \\
\hline No & 240 & 77.4 & 70 & 22.6 & \\
\hline \multicolumn{6}{|c|}{ History of congenital anomalies in offspring } \\
\hline Yes & 26 & 74.3 & 9 & 25.7 & \multirow{2}{*}{$\begin{array}{l}X^{2}=0.547 \\
P=0.460\end{array}$} \\
\hline No & 246 & 77.8 & 70 & 22.2 & \\
\hline
\end{tabular}

Moreover, believing in the importance of the tests was also significantly associated with willingness of women to undergo the test if recommended $(\mathrm{p}<0.001)$ (Table 5).

\section{DISCUSSION}

Studying the knowledge of women in Alexandria, Egypt towards prenatal screening showed that slightly less than half of studied women $(n=166,47.29 \%)$ were aware of the presence of accurate screening tests for congenital malformations. On the other hand, more in depth assessment of the knowledge of those women who were aware of the presence of screening tests revealed that the majority of them $(n=135,81.33 \%)$ were able to nominate at least one screening test. This level of knowledge among studied women is considered low compared to what was reported in a study carried out in Hong Kong in 2014 where $78.1 \%$ of studied women were aware of the presence of prenatal screening tests for Down syndrome and to what was reported in a study carried out in USA in 2011 where $98 \%$ of studied women reported their personal experience with prenatal testing during their pregnancies. $^{12,13}$ 
Table 5: Beliefs of studied women about congenital malformations and their attitudes towards PNS.

\begin{tabular}{|c|c|c|c|c|c|}
\hline \multirow{2}{*}{ Beliefs } & \multicolumn{2}{|c|}{ Accepting $(n=271)$} & \multicolumn{2}{|c|}{ Refusing or not sure $(n=79)$} & \multirow{2}{*}{$\begin{array}{l}\text { Test of } \\
\text { significance }\end{array}$} \\
\hline & no & $\%$ & no & $\%$ & \\
\hline \multicolumn{6}{|c|}{ Perceived seriousness of congenital malformations } \\
\hline Agree & 199 & 84.7 & 36 & 15.3 & \multirow{3}{*}{$\begin{array}{l}\mathrm{X}^{2}=24.549 \\
\mathrm{P}=<0.001 *\end{array}$} \\
\hline Not sure & 63 & 65.6 & 33 & 34.4 & \\
\hline Disagree & 9 & 47.4 & 10 & 52.6 & \\
\hline \multicolumn{6}{|c|}{ Perceived susceptibility to have a child with congenital malformations } \\
\hline Agree & 56 & 76.7 & 17 & 23.3 & \multirow{3}{*}{$\begin{array}{l}X^{2}=0.551 \\
P=0.759\end{array}$} \\
\hline Not sure & 150 & 76.5 & 46 & 23.5 & \\
\hline Disagree & 66 & 80.5 & 16 & 19.5 & \\
\hline \multicolumn{6}{|c|}{ Perceived inability to care of a handicapped child } \\
\hline Agree & 59 & 76.6 & 18 & 23.4 & \multirow{3}{*}{$\begin{array}{l}X^{2}=2.696 \\
P=0.260\end{array}$} \\
\hline Not sure & 133 & 74.7 & 45 & 25.3 & \\
\hline Disagree & 80 & 83.3 & 16 & 16.7 & \\
\hline \multicolumn{6}{|c|}{ Believing in the importance of PNS (for early detection) } \\
\hline Agree & 227 & 82.2 & 49 & 17.8 & \multirow{3}{*}{$\begin{array}{l}X^{2}=16.815 \\
P<0.001 *\end{array}$} \\
\hline Not sure & 37 & 60.7 & 24 & 39.3 & \\
\hline Disagree & 8 & 57.1 & 6 & 42.9 & \\
\hline
\end{tabular}

After informing studied women about the availability of prenatal screening tests, the majority of them $(77.5 \%)$ showed a positive attitude towards carrying out prenatal screening which is also considered lower than the finding of Dahl K et al (2006) ${ }^{(14)}$ who reported that up to $90 \%$ of studied pregnant women in Denmark expressed a positive attitude towards screening procedures in pregnancy.

On the other hand slightly more than half of women $(58.7 \%)$ were accepting termination of pregnancy if medically indicated in case of detection of severe congenital malformation. This finding may be attributed to the influence of religious ruling in Islamic countries as according to Qur'anic verses and Moslem Prophetic tradition, "The fetus becomes ensouled at 120 days gestation. However, abortion after 120 days is considered criminal offense and is prohibited by all Islamic Scholars". This is in addition to the strong belief in fate among Egyptians. ${ }^{15}$ On the contrary, the main influences for deciding termination after detection of congenital malformations in non-Islamic countries were the severity of malformations followed by socioeconomic considerations as disruption in employment, lack of resources or relation issues. ${ }^{16}$

Increasing woman's age was significantly associated with having a positive attitude towards carrying out prenatal screening $(\mathrm{P}=0.019)$ which was in agreement with Kosec $\mathrm{V}$ et al. ${ }^{17}$ This may reflect the woman's knowledge of the link between that biological risk and the occurrence of congenital malformations. In addition, on assessing the effects of the socioeconomic characteristics of studied women on their attitude towards carrying out prenatal screening, it was revealed that increasing the level of education, being a working woman, and living in an urban area were significantly associated with a positive attitude
( $\mathrm{P}=0.026, \quad \mathrm{P}=0.005, \mathrm{P}=0.046$ respectively). Positive attitude towards PNS among those with higher level of education might be attributed to their higher level of knowledge about the different test aspects. ${ }^{18}$ Moreover, increasing the women's social level (indicated by educational level, living in urban areas and working) may be associated with increasing the level of knowledge of risks in pregnancy, decreasing fear from medical interventions, and increasing the acceptance of preventive measures and a more practical and scientific way in thinking and decision making.

Congenital malformations are considered as a major cause of infant morbidity and mortality globally. Giving birth to a child suffering from congenital anomaly is associated with a marked psychological and social impact on all the family members especially in developing countries. The marked advances in prenatal screening for congenital malformations offer a good opportunity for early diagnosis and decision making in early management of the condition. ${ }^{9}$ These facts were reflected on the motives for carrying out PNS as reported by studied women where the significant motives revealed were the perceived seriousness of congenital malformations followed by the perceived importance of the test for early detection of malformations ( $\mathrm{P}<0.001)$.

So, there is a marked need for increasing the awareness of Egyptian women in the reproductive age about the availability of different prenatal screening tests for congenital malformation, the accuracy and safety of these tests, and parents gain from early detection of congenital malformations in their offspring. These messages should be provided to every woman especially those with a greater risk during premarital, preconception and antenatal care services. More efforts are needed to reach women who 
have a lower level of education, house wives, and those living in rural areas. Engaging husbands also is important because of their main role in decision making. Being an Islamic country also make the role of Fatwa in changing women attitude towards prenatal screening and termination of pregnancy very influential. It is also recommended to have a Moslem religious cleric in the committee who advised for termination of pregnancy in cases of detection of severe congenital malformation.

Funding: No funding sources

Conflict of interest: None declared

Ethical approval: The study was approved by the Institutional Ethics Committee

\section{REFERENCES}

1. WHO (2016): Congenital anomalies. Fact sheet. Available

from http://www.who.int/mediacentre/factsheets/fs370/en. Accessed on 24\10\2016.

2. Mazer P, Gischler S, Koot H, Tibboel D, Dijk M, Duivenvoorden $\mathrm{H}$. Impact of a child with congenital anomalies on parents (ICCAP) questionnaire; a psychometric analysis. Health Quality Life Outcomes. 2008;6(1),102-12.

3. Taanila A, Syrjälä L, Kokkonen J, Järvelin MR. Coping of parents with physically and/or intellectually disabled children. Child: Care, Health Dev. 2002;28(1):73-86.

4. Sheridan E, Wright J, Small N, Corry CP, Oddie S, Parslow R et al. Risk factors for congenital anomaly in a multiethnic birth cohort: an analysis of the Born in Bradford study. Lancet. 2013;382:1350-9.

5. Ahmed A, Abd el Kader, Abd El Hamid, Gaafar M. Assessment of risk factors for fetal congenital anomalies among pregnant women at Cairo University Hospitals. J Am Sci. 2011;7(11).

6. Tayebi N, Yazdani K, Naghshin N. The prevalence of congenital malformations and its correlation with consanguineous marriages. Oman Med J. 2010;25(1):37-40.

7. Egypt Demographic and Health survey (2008): Infant mortality rate. online at dhsprogram.com/pubs/pdf/fr220/fr220.pd

8. Mohammed A, Mohammed S, Abdul-Fatah AM. Congenital Anomalies among Children: Knowledge and Attitude of Egyptian and Saudi Mothers. J Biol Agr Healthcare. 2013;3(20):19-32.

9. Routine Care for the Healthy Pregnant Woman. NICE Clinical Guidelines, No. 62. National Collaborating
Centre for Women's and Children's Health (UK). London: RCOG Press; 2008.

10. Lawson KL, Pierson RA. Maternal decisions regarding prenatal diagnosis: rational choices or sensible decisions? J Obstet Gynaecol Can. 2007;29(3):240-6.

11. Dahl K, Hvidman L, Jørgensen FS, Kesmodel US. Knowledge of prenatal screening and psychological management of test decisions. Ultrasound Obstet Gynecol. 2011;38(2):152-7.

12. Sylvia SN, Lin Wai Chan, William WK. Pregnant women's attitudes to and knowledge of non-invasive prenatal testing in Down syndrome screening in Hong Kong. HKJGOM. 2014;14(1):43-50.

13. Norton ME, Nakagawa S, Kuppermann M. Women's attitudes regarding prenatal testing for a range of congenital disorders of varying severity. J Clin Med. 2014;3:144-52.

14. Dahl K, Kesmodel U, Hvidman L, Olesen F. Informed Consent: attitudes, knowledge and information concerning prenatal examinations. Acta Obstet Gynecol Scand. 2006;85(12):1414-9.

15. Shaikh S. Family planning, contraception and abortion in Islam: Undertaking Khilafah: Moral agency, justice and compassion. In: Maguire, D., Ed., sacred choices: The case for contraception and abortion in world religions, Oxford University Press, Oxford; 2003:1-4.

16. Asplin N, Wessel H, Marions L, Georgsson S. Pregnant women's perspectives on decision making when a fetal malformation is detected by ultrasound examination. Sexual Reproduc Healthcare. 2013;4:79-84.

17. Kosec V, Zec I, Tislarić-Medenjak D, Kuna K, Simundić AM, Lajtman-Krizaić M et al. Pregnant women's knowledge and attitudes to prenatal screening for fetal chromosomal abnormalities: Croatian multi-centric survey. Coll Antropol. 2013;37(2):483-9.

18. Dahl k, Hvidman L, Jorgensen FS, Henriques C, Olesen F, Kjaergard H, et al. First trimester Down syndrome screening: pregnant women's knowledge. Ultrasound Obstet Gynecol. 2011;38:145-51.

Cite this article as: El-Said R, El-Weshahi HT, Ashry MH. Knowledge, attitudes and beliefs of women in the reproductive age towards prenatal screening for congenital malformations, AlexandriaEgypt. Int J Reprod Contracept Obstet Gynecol 2017;6:1707-12. 